\title{
An Overview on Preparation and TL Characterization of Lithium Borates for Dosimetric Use
}

\author{
E. Pekpak ${ }^{1, *}$, A. Yılmaz ${ }^{2}$ and G. Özbayoglu ${ }^{3}$ \\ ${ }^{I}$ Middle East Technical University, Mining Engineering, Ankara, Turkey \\ ${ }^{2}$ Middle East Technical University, Mining Engineering, Ankara, Turkey \\ ${ }^{3}$ Dean of Faculty of Engineering, Attlim University, Ankara, Turkey
}

\begin{abstract}
Boron that appears in borate form in nature is an essential additive to a variety of industrial products. Recently, certain boron compounds have attracted attention in high technology utilization areas owing to their special crystal and optical characteristics. Thermoluminescent (TL) dosimetry that is used to record amount of radiation exposure is one of such areas. Two borates searched for candidacy in TL dosimetry are lithium tetraborate and lithium triborate. These materials are synthesized and metal doped by numerous researchers to be tested for thermoluminescence response. Lithium tetraborate has aroused interest of scientists since $1960 \mathrm{~s}$ by the courtesy of the thermoluminescence (TL) property. However, lithium triborate is rather new in this area. This study compromises a broad overview including synthesis methods employed for the production of these two materials. Furthermore, the TL properties that have significant effect on the TL dosimetry potential of a compound are noted along with the detailed information on TL measurement procedure specifications.
\end{abstract}

Keywords: Thermoluminescence, dosimetry, lithium borates, synthesis, doping, characterization.

\section{BORATES}

There are several natural and synthetic borates used in different branches of industry. Natural borates are generally cleaned from their impurities in processing plants and are further treated to more qualified end products (like boric acid, anhydrous boric acid, anhydrous borax, borax pentahydrate,borax decahydrate and sodium perborate) in recrystallizer units. Besides, the variability of borate crystal chemistry [1] allows researchers synthesize numerous borate structures usable in high technology areas. Thermoluminescent (TL) dosimetry used to measure radiation exposure is an important high technology utilization area for these synthetic borates.

\subsection{General Uses of Borates in High Technology}

It is certain that the interesting crystal structure of borates play an important role for its utilization in high technology. Although the utilization variety of borates is strongly related to its structural variety, in this communication we will concentrate on results of these characteristics rather than chemical background. Indeed, there is extensive number of studies devoted to the crystal structures of borates [1-3] which may be refered for detailed information.

Owing to the varied crystallinity borates possess large electronic band gaps, attractive nonlinear optical (NLO) properties, chemical and environmental stability, and mechanical strength [3]. Hence, they found wide use in

*Address correspondence to this author at the Middle East Technical University, Mining Engineering, Ankara, Turkey; Tel: +903122102664; Fax:+903122105822; E-mails: epekpak@metu.edu.tr, ayseny@metu.edu.tr nonlinear optical technologies as well as in thermoluminescence dosimetry.

Borates have high UV transmittance at wavelengths down to $155 \mathrm{~nm}$ [4]. Therefore, they are appropriate for the use in plasma displays and in laser technology. Furthermore they are strong phosphors which give bright emission due to the strong absorption in vacuum ultra violet [3]. Borates like $\mathrm{CsLiB}_{6} \mathrm{O}_{10}$ and $\mathrm{K}_{2} \mathrm{~A}_{12} \mathrm{~B}_{2} \mathrm{O}_{7}$ discovered recently are reported to have NLO utilization potential generating ultra violet and vacuum ultra violet laser radiation [5].

Three major borates pronounced in TL dosimetry are magnesium tetraborate $\left(\mathrm{MgB}_{4} \mathrm{O}_{7}\right)$, barium betaborate $(\beta$ $\left.\mathrm{BaB}_{2} \mathrm{O}_{4}\right)$ and lithium tetraborate $\left(\mathrm{Li}_{2} \mathrm{~B}_{4} \mathrm{O}_{7}\right)$. In the recent years thermoluminescent properties of lithium triborate $\left(\mathrm{LiB}_{3} \mathrm{O}_{5}\right)$ has also attracted attention. Among these, "lithium triborate" and "lithium tetraborate" seem more attractive than the others regarding the personnel and medical dosimetry purposes. This is mainly due to the effective atomic number of these compounds which is very close to that of biologic tissue. Therefore, in the following sections these two materials are to be leaned over in detail.

\section{STRUCTURE OF LITHIUM BORATES}

There are three main stable compounds in the $\mathrm{Li}_{2} \mathrm{O}-\mathrm{B}_{2} \mathrm{O}_{3}$ system. They are lithium meta-borate $\left(\mathrm{LiBO}_{2}\right)$, lithium tetraborate $\left(\mathrm{Li}_{2} \mathrm{~B}_{4} \mathrm{O}_{7}\right)$, and lithium triborate $\left(\mathrm{LiB}_{3} \mathrm{O}_{5}\right)$. The major base units in the borate crystals are listed below [3]:

- simple trigonal and tetrahedral groups $\left(\mathrm{BO}_{3}\right)^{3-}$ and $\left(\mathrm{BO}_{4}\right)^{5-}$

- bitrigonal and ditetrahedral groups $\left(\mathrm{B}_{2} \mathrm{O}_{5}\right)^{4-}$ and $\left(\mathrm{B}_{2} \mathrm{O}_{7}\right)^{8-}$ 
- circular six-membered groups with a mixed coordination $\left(\mathrm{B}_{3} \mathrm{O}_{6}\right)^{3-},\left(\mathrm{B}_{3} \mathrm{O}_{7}\right)^{5-},\left(\mathrm{B}_{3} \mathrm{O}_{8}\right)^{7-}$, and $\left(\mathrm{B}_{3} \mathrm{O}_{9}\right)^{9-}$

- coupled double six-membered rings $\left(\mathrm{B}_{5} \mathrm{O}_{10}\right)^{5-}$

The basis for the structure of $\mathrm{LiBO}_{2}, \mathrm{LiB}_{3} \mathrm{O}_{5}$ crystals are $\left(\mathrm{BO}_{3}\right)^{3-}$ and $\left(\mathrm{B}_{3} \mathrm{O}_{7}\right)^{5-}$ respectively. The $\left(\mathrm{B}_{4} \mathrm{O}_{9}\right)^{6-}$ groups constitute base unit for $\mathrm{Li}_{2} \mathrm{~B}_{4} \mathrm{O}_{7}$ crystals.

\subsection{Properties of Lithium Borates}

\subsubsection{Properties of Lithium Tetraborates}

The physical, chemical and structural properties of lithium tetraborate play a major role on its potential as a TL dosimeter. The crystal structure and defect distribution are the most vital properties, but still characteristics like solubility and thermal behavior are determining factors for the production procedure.

Initially, lithium tetraborate is a white powder which does not have a distinctive odor. The melting point is $917^{\circ} \mathrm{C}$ and solubility is in the moderate range (1-10\%). The density of lithium tetraborate powder is $2.45 \mathrm{~g} / \mathrm{cm}^{3}$. Lithium tetraborate possesses numerous technological properties such as; pyroelectricity (heat induced electricity) and piezoelectricity (pressure induced electricity) [3].

Definitely, other technological features of lithium tetraborate leaded researchers to investigate its candidacy for thermoluminescence industry. For instance, lithium tetraborate acquires interesting optical properties. Thus, scientists directed their research on the investigation of linear and nonlinear optical (NLO) properties of lithium tetraborate. Sugawara (1998) made research on these properties and figured out that the material had a short wavelength cutoff of $160 \mathrm{~nm}$ and a suitable acceptance angle width, acceptance wavelength width and walk-off angle in the UV range. The shortest SHG output wavelength found was $243.8 \mathrm{~nm}$. Excellent transparency and low scattering are other superior characteristics of $\mathrm{Li}_{2} \mathrm{~B}_{4} \mathrm{O}_{7}$. Sugawara came into the decision that this sample is an exceptional nonlinear optical material for frequency conversion in the UV range. Lithium tetraborate is also known to have a high radiation resistivity and a wide operation dose range. Furthermore it is an important feature of lithium tetraborate that it is only weakly dependent on the dose on ionizing radiation energy [6].

All the technological properties of lithium tetraborate are due to its peculiar crystallization system. Lithium tetraborate crystallizes in tetragonal lattice point group with the cell dimensions of $a=9.47 \AA$; $c=10.86 \AA$ and point group of $4 \mathrm{~mm}$ [4]. A closer look at the lattice structure of lithium tetraborate reveals that lithium tetraborate is formed by two $\mathrm{BO}_{4}$ tetrahedra and two $\mathrm{BO}_{3}$ triangles. There are two non-planar, six membered rings in the group. The two boron atoms and one oxygen atom of the group are shared by two rings that are twisted. Each diborate unit is linked at corners of four boron atoms with bridging oxygens with identical diborate units to form a three-dimensional network.

\subsubsection{Properties of Lithium Triborates}

Lithium triborate is a chemically stable, mechanically strong material with hygroscopic characteristics [7]. It has a melting point of $834{ }^{\circ} \mathrm{C}$. It crystallizes in orthorhombic system and the unit cell parameters of lithium triborate are

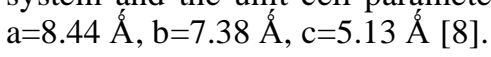

\subsection{Synthesis of Lithium Borates}

Lithium borates namely lithium tetraborate and lithium triborate produced by different methods to be used as TL dosimeters. The matrix can be synthesized in a number of forms from single crystal to powder. The final product gains distinctive thermoluminescence characteristics by addition of a variety of activators either during the production procedure or after formation of the main matrix.

\subsubsection{Synthesis of Lithium Tetraborate}

There is innumerous research devoted to the understanding of optimal synthesis conditions of lithium tetraborate. Although they suggest different methods of production, they do have certain common tendencies. Indeed, lithium tetraborate has been synthesized in the following forms: powder form, pellet form, glass or polycrystalline form or it can be melted and recrystalized to obtain a single crystal.

The powder lithium tetraborate is appropriate to be used for thermoluminescence dosimetry. In spite of the fact that powder lithium tetraborate is claimed to be inconvenient for the use in this area, Panasonic utilizes this product in TLD badges [9]. Hence, it is obvious that the problems faced during laboratory period can easily be overcome during the commercial stage by an automatic system, since the main difficulty is to get exactly the same weight of the powder during thermoluminescence measurements. Pradhan [10] emphasized the possibility of contamination of the powder as a demerit of this form. Nevertheless, once the powder product is placed on badges, they are covered with a thin, translucent layer of film which protects the dosimeter from getting polluted. The main advantage of powder production against other types is that the energy consumed during the process is noticeably less than that for glass and crystal formation since in each case higher temperatures are employed to melt material first.

There are a number of techniques to obtain lithium tetraborate as powder. It can be produced by heating of a hydrated precursor of lithium tetraborate [11]. The second technique is the wet reaction. This method was applied by Furetta [12] who performed wet reaction with stoichiometric amounts of $\mathrm{Li}_{2} \mathrm{CO}_{3}$ and $\mathrm{H}_{3} \mathrm{BO}_{3}$. The same method was applied by Prokic [9] in 2001 and Ege in 2007 [13]. Thirdly, solid state synthesis option was performed by Sangeeta [14] whose production procedure followed was milling and homogenizing $\mathrm{Li}_{2} \mathrm{CO}_{3}$ and $\mathrm{H}_{3} \mathrm{BO}_{3}$ powders and sintering the mixture at $700^{\circ} \mathrm{C}$ for 48 hours. Solid state synthesis was employed also by Jubera [15] who aimed at producing lithium rare earth borates with initial reactants of $\mathrm{H}_{3} \mathrm{BO}_{3}$ and $\mathrm{LiBO}_{2}$, $\mathrm{LiOH} . \mathrm{H}_{2} \mathrm{O}$. The heating route followed was keeping the mixture at $400{ }^{\circ} \mathrm{C}$ for 2 hours and at $700^{\circ} \mathrm{C}$ for a time span during which all the nitric acid vapors in the system, due to dissolving the constituents in nitric acid, could be evaporated. Then after, different sintering temperatures are chosen for different products. $\mathrm{Li}_{2} \mathrm{~B}_{4} \mathrm{O}_{7}$ : $\mathrm{Cu}$ in form of powder was prepared to study thermally stimulated luminescence materials in the radiotherapy [16]. 
The powder product form can be pressed into a pellet for ease in laboratory measurements and a better practicability. However, the pellets are recorded to be fragile entities and are vulnerable against breakage [10]. The high temperature solid state synthesis at two stages is another method used. Stoichiometric mixture of $\mathrm{Li}_{2} \mathrm{CO}_{3}$ and $\mathrm{H}_{3} \mathrm{BO}_{3}$ powders is heated at $400^{\circ} \mathrm{C}$ for three hours as an initial stage. While, the second stage heating is performed at $750^{\circ} \mathrm{C}$ for 4 hours with an intermittent mixing after the first 2 hours [17]. The expected reaction was:

$\mathrm{Li}_{2} \mathrm{CO}_{3}+4 \mathrm{H}_{3} \mathrm{BO}_{3} \rightarrow \mathrm{Li}_{2} \mathrm{~B}_{4} \mathrm{O}_{7}+\mathrm{CO}_{2}+6 \mathrm{H}_{2} \mathrm{O}$

The lithium tetraborate can also be synthesized in the form of glass. This technique lies at a place between powder product and single crystal when in terms of ease in production. The temperatures should be adjusted and controlled cautiously. Beyond that the heated sample should be cooled rapidly. However, one should note that the temperatures applied for glass lithium tetraborate production are higher than that for powder production. This is made in order to reach a molten state before cooling. Jaychandran [18] produced lithium borate glasses by pouring molten lithium borate into a stainless steel dish at room temperature and air-cooled the sample. In 2001, lithium tetraborate glass was synthesized by melting $\mathrm{Li} \mathrm{B} O$ with the molar ratio $\mathrm{B} / \mathrm{Li}$ of 2.00 in a Bridgman type furnace. And finally the doped dry material was maintained at $980^{\circ} \mathrm{C}$ for 1 hour to avoid bubbles [19]. In another experimental study, $\mathrm{Li}_{2} \mathrm{CO}_{3}$ and $\mathrm{H}_{3} \mathrm{BO}_{3}$ mixture was exposed to $950^{\circ} \mathrm{C}$ in a platinum crucible and then the temperature was increased up to $1150^{\circ} \mathrm{C}$ for the system to relieve from even small traces of water and carbon dioxide [20]. Manam [21] who followed "Schulman method" and mixed $\mathrm{Li}_{2} \mathrm{CO}_{3}$ and $\mathrm{H}_{3} \mathrm{BO}_{3}$ in stoichiometric ratios melted the mixture at $950^{\circ} \mathrm{C}$ in a silica crucible and allowed the material to cool rapidly to room temperature. Manam reheated this glassy mass to $650^{\circ} \mathrm{C}$ and kept for a retention time of half an hour which was followed by secondary cooling stage. The sample was then powdered by grinding and sieving.

The final technique of producing lithium tetraborate as a TL dosimeter candidate is single crystal growth. There are two basic methods to produce lithium tetraborate as single crystal: Bridgman method and Czochralski method named after Percy Williams Bridgman and Jan Czochralski respectively. Both of these methods require special systems which work on molten material cooled slowly in presence of a seed crystal.

The metals doped in lithium tetraborate up to date to trigger or enhance the thermoluminescent characteristics of lithium tetraborate are numerous: magnesium, indium, nickel, cerium, silver, europium, titanium, praseodymium, potassium, chromium, cobalt, dysprosium, iron, lanthanum, thulium, phosphorus, copper, manganese are the metals doped.

\subsubsection{Synthesis of Lithium Triborate}

Lithium triborate is rather new in TL dosimetry compared to lithium tetraborate. Hence, the synthesis studies therefore are considerably contemporary.

In 2006 (Ardıçoğlu), lithium triborate is synthesized in powder form. A homogenized mixture of stoichiometric quantities of reactants $\mathrm{Li}_{2} \mathrm{CO}_{3}$ and $\mathrm{H}_{3} \mathrm{BO}_{3}$ were heated at $750^{\circ} \mathrm{C}$ for 14 hours. The expected reaction was:

$$
\mathrm{Li}_{2} \mathrm{CO}_{3}+6 \mathrm{H}_{3} \mathrm{BO}_{3} \rightarrow 2 \mathrm{LiB}_{3} \mathrm{O}_{5}+\mathrm{CO}_{2}+9 \mathrm{H}_{2} \mathrm{O}
$$

Moreover, in 2007, the same method was employed for the production of lithium triborate in the study of Özdemir [22]. However the activators employed in these two studies were different. Ardıçoğlu [23] studied different concentrations of $\mathrm{Gd}_{2} \mathrm{O}_{3}$ as activator while the dopants added by Özdemir [22] were $\mathrm{Al}_{2} \mathrm{O}_{3}, \mathrm{CuO}, \mathrm{MnO}_{2}$, and $\mathrm{MgO}$.

\subsection{Uses of Lithium Borates}

The large group of borates is an attractive chemical playground adopted by many researchers and groups. Noteworthy attention is directed towards lithium borates due to the attractive features that their interesting chemical structure provides. These properties of lithium borates opened the gates of different utilization areas for them.

Initially, lithium borates are used in surface acoustic wave (SAW) devices of electric circuits. Such devices convert acoustic wave to electrical signal and vice versa making use of the piezoelectric effect of certain materials. The major materials used in this area are quartz, lithium niobate, lithium tantalate, lanthanum gallium silicate and lithium tetraborate is proved to be a pretty logical alternative $[6,19,20,24$, 25]. Moreover, lithium borates are known to be used in sensors like pressure sensors and pyroelectric sensors [24]. Owing to their non linear optical properties this material finds use as ultraviolet frequency converter in lasers.

\section{THERMOLUMINESCENCE}

Pradhan [10] defines thermoluminescence simply as "the phenomenon of light emission caused by heating of a preirradiated TL material. Although the concept can be defined in a straightforward way, it has a quite complicated mechanism behind.

Application of radiation to a thermoluminophore triggers occurrence of mobile holes and electrons in the crystal structure of the material. There are hole traps and electron traps by which the holes and electrons are captured. There is a relation between the amount of occupied traps and radiation applied [26]. The system can be explained by the assumption that at least two imperfections exist in the structure of a thermoluminescent material. Upon radiation, pairs of electrons and holes are produced. After the first excitation one of the imperfections captures the electron and the other imprisons a hole. These imperfections possess different metastable trapping states and energies related to the energy bands they are in. After the irradiation, heating of the samples releases the electrons to the conduction band by which the electron may recombine with the trapped holes which results in emission of photons. At this stage the hole traps are named as the "luminescent" or "recombination center" [27].

\subsection{Use of TL and TL Dosimetry}

There are three major area of utilization thermoluminescence. They are geological dating, archeological aging and radiational dosimetry. Thermoluminescence dating in geology is especially appropriate for the samples that are younger than one million years which are quite difficult to age with classical methods. In archeometry, TL dosimetry 
has been used for potteries and fossils. The natural thermoluminescence output obtained by the read out in aging applications is related to sensitivity, dose and time from the formation of the sample. Therefore, from an equation including these parameters one may easily calculate the age of the sample [10, 26, 27].

Secondly, thermoluminescence finds extensive use in "radiation dosimetry". In other words, it is used to determine the amount of radiation that a person is exposed to either from the working environment or due to medical treatment (in cancer treatments). In personnel dosimetry the employee is provided with the apparatus containing the thermoluminophore, namely the dosimeter, and the amount of radiation that he/she is exposed to is measured periodically. These measurements are of great importance regarding the occupational health and safety aspect. The authority is responsible for the health of its employees and the situation is quite serious in the working places with such a severe health risk like radiation. These work places include nuclear stations and radiotherapy departments of hospitals. Besides, it is of significance to monitor the amount of radiation a patient is given. For this purpose in-vivo (in-body) dosimeters are developed to monitor the success of the treatment applied.

\subsection{Requirements of Personnel Dosimetry}

Dosimeters have different properties depending on their constituents. Moreover, the dosimeter is supposed to have certain properties specific to a peculiar to the area of utilization. Nonetheless, there are a quantity of basic requirements that all TL dosimeters are expected to fulfill. Below given is a list of the features that a TL material is desired to have to be a TL dosimeter $[10,28,29]$.

1- The dosimeter is desired to give simple isolated glow curve preferably with a single glow peak around $200^{\circ} \mathrm{C}$ $\left(180-250^{\circ} \mathrm{C}\right)$ should be displayed. However, in case of a complex glow curve at least the main peak should be well resolved. When the peak is displayed at higher temperatures, infrared emissions from the sample and/or sample holder may interfere with the results which may give rise to errors in interpretations.

2- It is expected that it has high gamma ray sensitivity is desired. The dosimeter is also expected to have high signal per unit of absorbed dose i.e. it should have high sensitivity.

3- Fading, loss of TL signal, must be low. Indeed, the dosimetric information should be kept in the dosimeter for sufficiently long time at a stable level. This is important when the readouts cannot be performed quickly after each exposure.

4- The response should be directly proportional to the dose applied in a wide range.

5- Sometimes, it may be necessary to carry out successive readouts. In this case the pre-radiational information should be erased totally before repeating the procedure. In general it is achieved by a heating procedure called "annealing". This procedure should be as easy as possible.

6- The TL dosimeter must be resistive to extreme climatic conditions and chemically inert. Dosimeter should be resistant against humidity, gases, moisture, organic solvents.

7- The sunlight should not affect the dosimeter to a serious level ideally dosimeters should be totally insensitive to light.

Added to these features it is advantageous that the dosimeter be appropriate for postal service and be cheap. It is vital that it is not toxic in case of in-vivo i.e. in the body testing. High accuracy and precision are other critical properties. For the use in personnel and medical dosimetry, it is severely important that the dosimeters have effective atomic number close to that of the human tissue.

Up to date, no TL material is encountered to satisfy all of the properties listed above in a perfect way. There are a number of commercial TL dosimeters used in sector each having different combination of features, different advantages and disadvantages against the others. But yet no perfect dosimeter could be reached in terms of production and utilization.

\section{TL PROPERTIES OF LITHIUM BORATES}

Specification of thermoluminescence characteristics of a candidate for TL dosimetry is an important step in production of a TL. Sensitivity, linear dose response, minimum detectable dose, shape and structure of the glow curves, the occurrence temperature and intensity of TL peaks, fading, sunlight susceptibility, and vulnerability against humidity should be studied. The TL properties of lithium tetraborate have been extensively researched. Hence all TL properties cited above are determined by numerous researchers. Nevertheless, the same is not valid for lithium triborate which is quite new in TL dosimetry investigations. It is beneficial to touch the nomenclature before providing related research on each of the characteristics.

\subsection{Sensitivity}

To begin with, scientists measured TL sensitivity in different units and determined via different methodology. Prokic [30] had an integrative approach and defined sensitivity as the area under the glow curve per unit weight of the dosimeter and per unit dose of gamma rays given to the dosimeter. Prokic found that copper silver and phosphor doped lithium tetraborate, is 5 times more sensitive compared to a commercial TL dosimeter (LiF:Mg,Ti (TLD-100)). On the other hand, formerly Pradhan [10] made a different definition. He explained sensitivity in terms of the quantity of light that the material emits per unit radiation dose. This definition is in complete compliance with the definition in "Handbook of Thermoluminescence" [29] which expresses sensitivity in terms of TL response per unit dose and unit mass of sample. According to the research of Wall [31], the sensitivity of the home made $\mathrm{Li}_{2} \mathrm{~B}_{4} \mathrm{O}_{7}: \mathrm{Cu}$ was approximately twice that of LiF: Mg, Ti. Earlier, Jayachandran et al. [18] discovered that the sensitivities of manganese doped lithium borate and of LiF (commercially TLD-100) were approximately equal. Fernandes et al. [32] who studied sensitivity extensively made relative sensitivity comparisons between commercial dosimeters TLD100, TLD700H, D-3-2 and lithium tetraborate with copper. 
For lithium triborate the sensitivity of $5 \% \mathrm{Al}$ doped sample is measured to be 2 times less than the peak 5 of TLD-100 [33].

\subsection{Linear dose Response}

Linear dose response is another critical characteristic. This property shows that the response displayed by the material is directly proportional to the dose of radiation that it is exposed to. Indeed this property is one of the advantages of lithium tetraborate over the other TL dosimeters.

Lithium borate possesses perfect linearity, when doses up to $10^{3}$ Gy are applied. Linearity can be observed rarely over $10 \mathrm{~Gy}$ which makes lithium borates rather distinct amongst others. The other TL materials usually display supralinear characteristics (Fig. 1) [12, 30, 34].

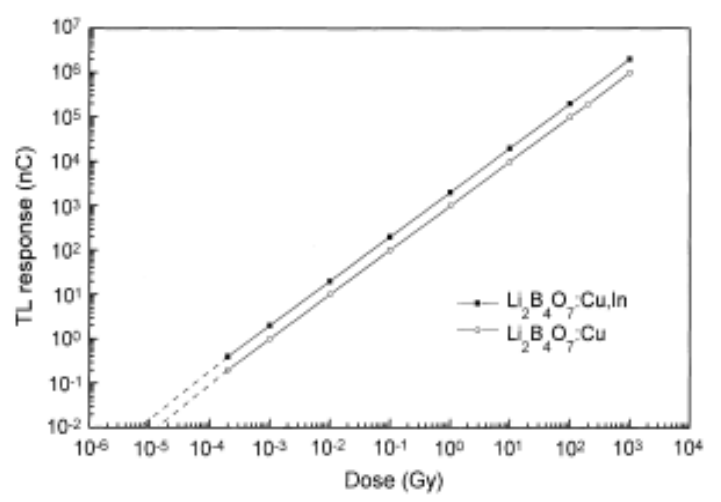

Fig. (1). TL response vs. c dose of lithium borate sintered TL dosimeters.

Undoubtedly, like in all TL properties, the dopants added play a major role in linear dose response. The product of Park's [35] study displays another aspect of this effect by comparing the linearity for manganese, copper and magnesium activated lithium tetraborate in Fig. (2). According to the study conducted it was recorded that all three dopants $(\mathrm{Mn}, \mathrm{Cu}$ and $\mathrm{Mg}$ ) retained linearity. Yet, there were differences between the inclinations of the fit lines drawn. The fit line for copper was rather steep while magnesium showed a milder inclination. This feature of lithium borates is assigned to the activator effect of copper doped in the material [36]. Linearity measurements performed on copper doped and manganese doped lithium tetraborate exhibit that copper doped sample has tendency to show supralinearity for 100 Gy dose while manganese doped sample is superlinear at about 10 Gy $[31,37,38]$. It is possible to observe that supralinearity in case of copper is lower.

Lithium triborate is proved to display this property up to 10 Gy. Fig. (3) plotted for dose response of lithium triborate shows the linearity and supralinearity areas [33].

\subsection{Minimum Detectable Dose}

Threshold dose is studied to determine the minimum dose that can be detected by the dosimeter. This characteristic also named as lowest level of detection. A more official definition is "the dose which gives three times the standard deviation of the zero doses reading of the dosimeter". El-Faramawy et al. [39] determined this value as 20Gy.
However this value went down to $6 \mathrm{~Gy}$ in the investigation executed by Prokic [30].

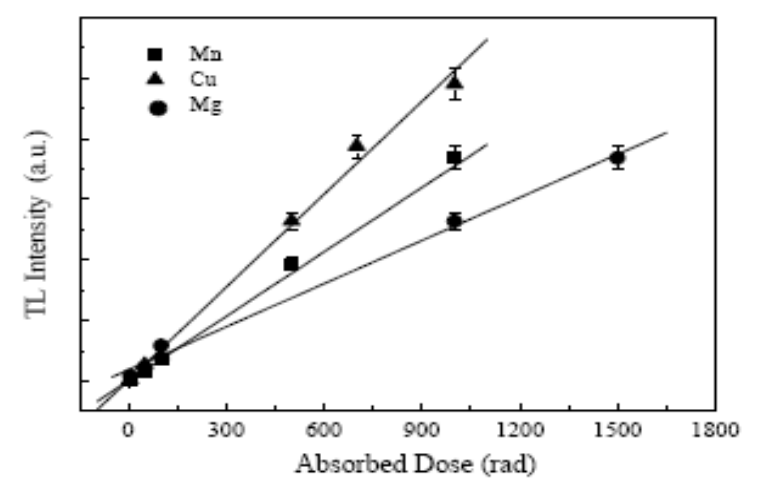

Fig. (2). TL intensity as a function of X-ray dose for different dopants.

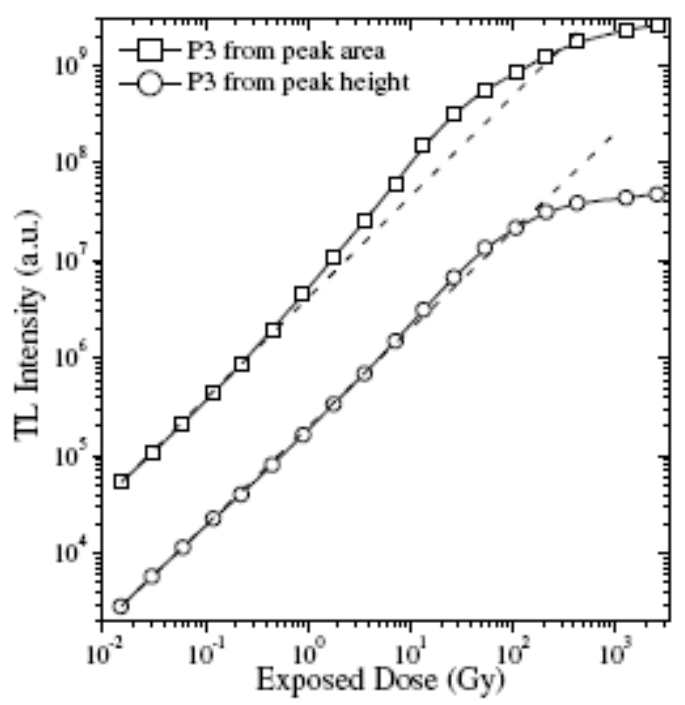

Fig. (3). Absorbed dose response of Al-doped lithium triborate.

\subsection{Glow Curve}

The glow curve is a plot generated by software connected to TL measurement systems. In this plot the thermoluminescence intensity (ordinate) versus temperature (abscissa) that increases up to a certain value with a definite rate during the read out is illustrated. The peaks observed on this curve correspond to the ionization of traps at various energy levels. The intensity axis of the plot gives a clue about the relative populations of electrons in different traps [26].

The glow curves are particularly important since they are the main indicators of whether a material can be used for TL dosimetry purposes or not. Generally it is desired that the glow curve gives a simple, if possible single, peak at around $200^{\circ} \mathrm{C}$. The peaks observed at low temperatures in the proximity of $100{ }^{\circ} \mathrm{C}$ fade away quickly hence they do not yield any information about the radiation content. Generally, this maximum is not symmetric and the half-width of this peak is wide. These properties of a shoulder peak imply that it has a complicated nature. Such maxima are claimed to root from superposition of a number of local trapping levels [6]. In a similar way, peaks observed around $300{ }^{\circ} \mathrm{C}$ are not assigned 
to good TL properties. Glow curve shapes and peak temperatures are also affected from the synthesis and doping methods [40].

Copper activated lithium tetraborate in one study [39] was recorded to give two peaks at 120 and $178^{\circ} \mathrm{C}$. As mentioned above, the low temperature peak encountered rapid fading. There is a common procedure applied to avoid such unnecessary peak. This procedure is called pre-readout annealing (application of a heat treatment to erase signal). However pre-readout carries to risk of total loss of signal recorded. Another custom to be followed is performing the readings after $24 \mathrm{~h}$ from the irradiation process [39]. The results of the research conducted by Furetta on copper and indium activated lithium tetraborate [12] resulted in two well separated peaks at 125 and $210{ }^{\circ} \mathrm{C}$. One three peak glow curve for copper doped lithium tetraborate was obtained by Manam et al. [21] which yielded the maxima at $175{ }^{\circ} \mathrm{C}$ although it had two more peaks at 290 and $350{ }^{\circ} \mathrm{C}$. Moreover, Prokic [9] stated that lithium tetraborate doped with copper, silver and indium together brings about a glow curve with peaks at $190{ }^{\circ} \mathrm{C}$ as main one and at 125 and $225^{\circ} \mathrm{C}$ as shoulders. One year later Prokic [30] found out the major and minor peaks at $185-190{ }^{\circ} \mathrm{C}$ and $135^{\circ} \mathrm{C}$ respectively for copper, silver and phosphor doped lithium tetraborate. Sangeeta et al. [14] obtained very similar results with $190{ }^{\circ} \mathrm{C}$ and $130{ }^{\circ} \mathrm{C}$ Wall et al. [31], observed the low temperature peak at $160^{\circ} \mathrm{C}$ for lithium tetraborate possessing copper, copper and silver, manganese as activator. Cuong et al. [14] who investigated the optimum copper concentration as dopant in lithium tetraborate obtained a series of glow curves with major peaks at $230^{\circ} \mathrm{C}$. Most recently, in 2009 copper and silver doped lithium tetraborate displayed major glow peaks between 185 to $235^{\circ} \mathrm{C}$ [17].

The intensities of these peaks provided in literature are given in arbitrary units therefore mainly they can be used in comparative manner. Indeed, in all cases there are several parameters that affect the shape, size and location of the glow curve. These parameters may be listed as: heating rate, radiation dose, pre- and post-irradiation heat treatments and activator used [10]. Certainly preparation method, $\mathrm{Li}_{2} \mathrm{O}$ $\mathrm{B}_{2} \mathrm{O}_{3}$ system, basic chemicals used, concentrations are other major factors influencing glow curve and the TL intensity [30].

The glow curve recorded for lithium triborate showed that for $\mathrm{Al}$ doped samples the major peak was at $218 \pm 2^{\circ} \mathrm{C}$ [33] which is a favorable property considering the radiational dosimetry potential. It was formerly proved by Özdemir [22] that lithium triborate had 2 thermoluminescence peaks, one at 137 and the other and the main at $200{ }^{\circ} \mathrm{C}$.

Fig. (4) is devoted to the glow curves of lithium tetraborate doped with $0.1 \% \mathrm{Cu}$ as the main activator assisted by 0.01-0.05\% Ag co-dopant (Pekpak 2009). Fig. (5) on the other side displays the glow curves for lithium triborate doped with $1 \% 2.5 \%$ and $5 \% \mathrm{Al}_{2} \mathrm{O}_{3}$ [33].

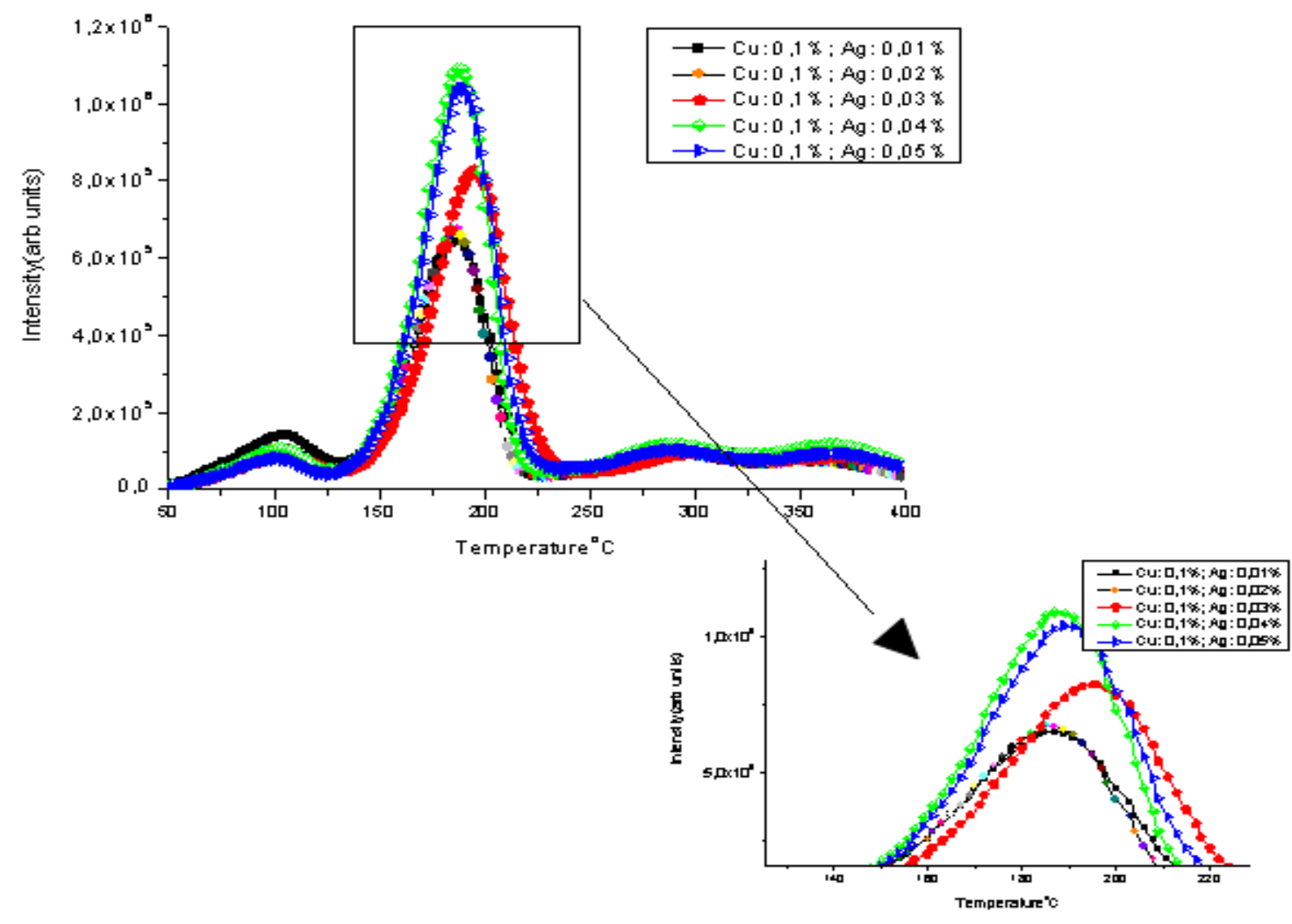

Fig. (4). Glow curves of lithium tetraborate doped with copper and silver. 


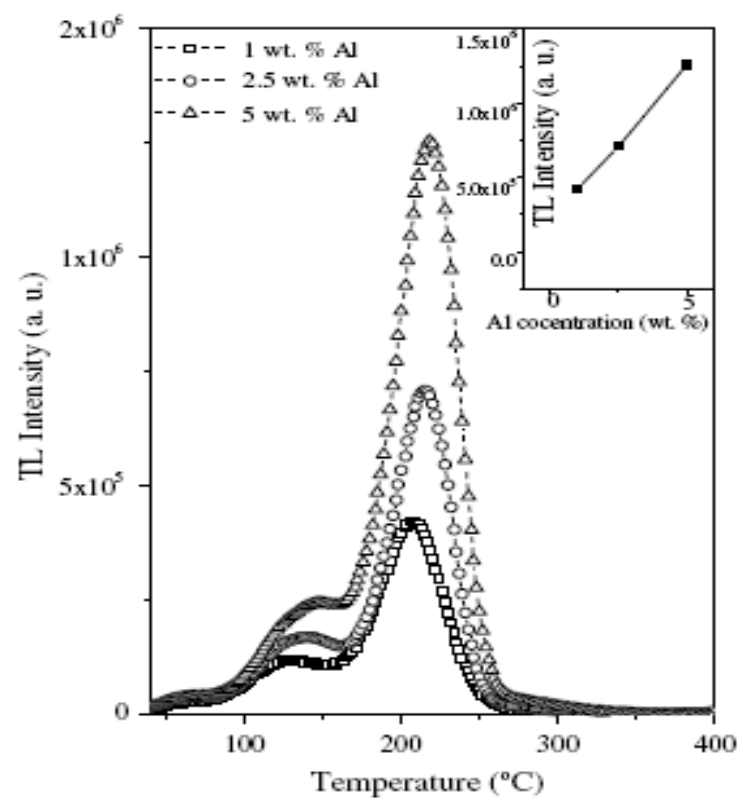

Fig. (5). Glow curves of lithium triborate doped with alumina.

\subsection{Fading}

Fading is designated by a decrease in the intensity of a peak in glow curve a time span. Certainly, material to be used for TL dosimetry purposes is required to have low or no fading so that accredited results can be obtained. Thus, fading can be regarded as a quality indicator for the dosimeter.

El- Faramawy et al. [39] declared that the samples from his study faded $1.7 \%$ the first day, $7 \%$ in the first month, 8.8 $\%$ at the end of the second month and $11 \%$ after the third month. The sample of Furetta's [12] study displayed similar fading with a percentage of $10 \%$ in three months. Wall et al. [31] was capable of producing manganese doped lithium tetraborate which faded only $5 \%$ in a month although the copper or copper and silver doped samples' signal was weakened about $60 \%$ in a week. Prokic [30] obtained samples for which the main peaks faded $10 \%$ in the first three months which is a quite slow rate of fading. In this study the peak at the low temperature region faded in 48 hours.

Lithium tetraborate doped with copper is generally quite sensitive to light. Therefore, light exposure is a determining factor in fading characteristic of lithium tetraborate. This subject is worked by Furetta [12] who proved that copper activated lithium tetraborate loses its TL intensity about 5 times when it was kept at sunlight for 3 hours. When the sample was exposed to the room light only, the fading resulted was less than $10 \%$ in 6 hours. According to the research of Wall et al. [31], fading is quite attention taking when the samples are exposed to tungsten or fluorescent light Fig. (6).

The fading studies performed on lithium triborate showed that the TL signal is lost about $5 \%$ in one month [33].

Humidity is another effective condition that should be taken into account during thermoluminescence studies. However, lithium tetraborate this is not severely affected by humidity. Wall et al. [31] has declared that a signal loss of 10 to $25 \%$ in 2-3 months in an environment where the relative humidity is $95 \%$ is a comparably small effect. Hence, copper doped lithium tetraborate is only slightly affected by humidity. The research conducted by Prokic [30] revealed that when two samples of copper, silver and phosphor doped lithium tetraborate are maintained in a humid condition $(90 \%$ relative humidity) and in dry atmosphere (15\% humidity) and when the TL responses are compared no significant difference due to humidity is observed. In such cases the main peak is not affected by the moist conditions.

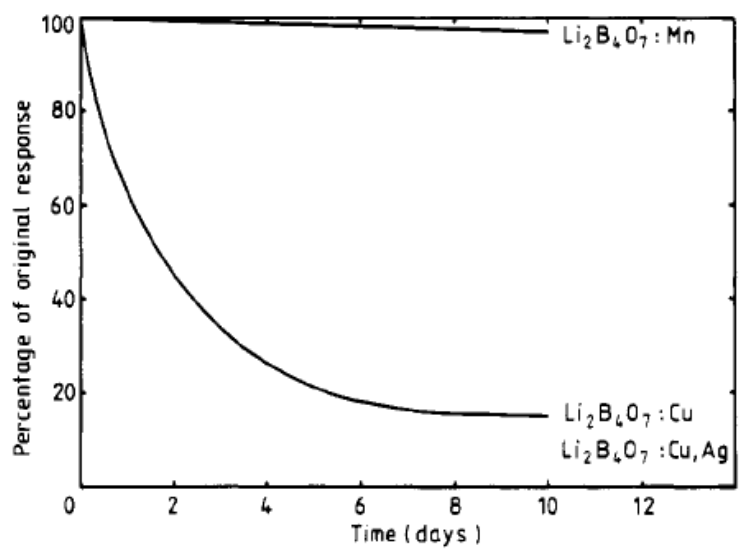

Fig. (6). Fading of dose signal when phosphors exposed to fluorescent and tungsten light.

As a result of the studies conducted on TL properties of lithium borates it is found that lithium tetraborate doped with copper and in some cases a coactivator is a sensitive dosimeter when compared to the commercial dosimeters. Furthermore, it has a very distinctive and significant property which is linear dose response. Linearity is quite a rare property among dosimeters. The glow curves obtained from TL measurements display resemblance. Generally the first peak around $100^{\circ} \mathrm{C}$ easily fades away and the main peak is around $200^{\circ} \mathrm{C}$ which stays steady under normal conditions for a period of time. Certainly the TL signal cannot be stored in dosimeter forever. And this span determines the fading property of the material. Fading of lithium tetraborate is in acceptable limits and can even be claimed to have low fading. It is not severely affected by humidity of the environment although exposure to direct sunlight may fasten the loss of TL signal. This is why lithium tetraborate based dosimeters should be protected from direct sunlight until the TL measurement.

Lithium tetraborate is well defined in terms of TL characteristics however lithium triborate can be studied more extensively for the specification of all TL properties.

\subsection{Defect Structure of Lithium Borates}

It is a fact that crystals are not always in perfect shape but they usually possess imperfections in their structure that are responsible for the unusual properties of materials. The interaction of lithium oxide and boron oxide causes attachment of an additional oxygen atom to the boron- oxygen triangle to produce boron oxygen tetrahedron. This boron- 
oxygen tetrahedron has excessive negative charge compensated by lithium cation located in the vicinity of the tetrahedron. In the absence of the lithium atom, this complex acts as a negative point defect forming hole traps that balance the negative charge in normal conditions. Conversely, a positively charged point defect results when oxygen vacancies take place. These positively charged traps may trap electrons in the first place [17]. These point defects act as hole traps and electron traps during the TL mechanism as explained in Section 3-Thermoluminescence.

\subsection{Effective Atomic Number}

Lithium tetraborate is in use in personnel dosimetry. Lithium triborate is confirmed to be suitable for utilization in this area. It may be vital that the dosimeter gives the exact amount of radiation that the user is exposed to, independent of the incident energy of the photons (Furetta, 2000). Therefore, the dosimeter is supposed to possess nearly the same atomic composition as that of the human tissue. This concept can be evaluated by the parameter of effective atomic number $\left(\mathrm{Z}_{\mathrm{eff}}\right)$ which should be as close as possible to that of human tissue (7.42.). Such materials display similar elemental composition and density with the human tissue [13] which in advance brings about the interpretation that the dose responses they reflect would be more reliable than those that do not have this property.

Tissue equivalency is rare among the dosimeters and the dosimeter which satisfies this requirement the best is lithium tetraborate. Tissue equivalency becomes rather important in case the $X$ radiation energy is in the region between 20 and $100 \mathrm{keV}$. At these energies the photoelectric interaction is predominant and dependent on the third power of the atomic number, so in that region of energies there is an overresponse in case of materials having a high atomic number [12]. Pradhan [10] determined the effective atomic numbers separately for lithium, boron and oxygen. The effective charge for lithium is between 0.7 and 0.9 . This value is $1.23^{ \pm} 0.05$ for boron and $0.93^{ \pm} 0.01$ for oxygen. Moreover, it is quite easy to calculate the $\mathrm{Z}_{\mathrm{eff}}$ of a material with a simple equation

$Z_{\text {eff }}=\sqrt[2,94]{\left(f_{1} x Z_{1}^{X}+f_{2} x Z_{2}^{X}+f_{3} x Z_{3}\right.}$

Where $f_{n}$ is the fraction of total number of electrons associated with each element $Z_{n}$ is the atomic number of each element and $\mathrm{x}$ is the coefficient related to the interaction of atoms.

For the case of lithium tetraborate $\left(\mathrm{Li}_{2} \mathrm{~B}_{4} 0_{7}\right)$ :

$\mathrm{Z}_{\mathrm{Li}}=3$

$\mathrm{Z}_{\mathrm{B}}=5$

$\mathrm{Z}_{\mathrm{O}}=8$

Total number of electrons per lithium tetraborate molecule is: 82 . Therefore the $\mathrm{f}$ values are:

$\mathrm{f}_{\mathrm{Li}}=0.073171$

$\mathrm{f}_{\mathrm{B}}=0.243902$

$f_{O}=0.682926$
The Li-B bonds in lithium tetraborate are ionic in characteristics. The $\mathrm{x}$ value which lies between 1 and 5 is 4 for the case of lithium tetraborate. As the calculation below implies the result form the effective atomic number is very close to the value given for biologic tissue in literature as 7.3 or 7.4 (Furetta , 2003; Prokic, 2002; Pradhan, 1981). Hence, inserting the related terms into equation (1)

$$
Z_{\text {eff }}=\sqrt[4]{\left(0,073171 \times 3^{4}+0,243902439 \times 5^{4} 0,682926829 \times 8^{4}\right.}
$$

$\mathrm{Z}_{\mathrm{eff}}=7.37$

Total number of electrons per lithium triborate molecule is: 58 . Therefore the $f$ values are:

$\mathrm{f}_{\mathrm{Li}}=0.051724$

$\mathrm{f}_{\mathrm{B}}=0.258621$

$\mathrm{f}_{\mathrm{O}}=0.682955$

And the resultant effective atomic number is:

$Z_{\text {eff }}=7.39$ which is considerably near the effective atomic number of human tissue.

\subsection{TL Measurement of Lithium Borates}

The here are three steps in TL measurement of a synthesized dosimeter candidate. These steps are annealing (if necessary), radiation exposure, read out. Annealing is not a step taken in the read outs carried out while the dosimeter is being used. Yet, it may be necessary when a new material is being studied as a potential TL dosimeter. Annealing is applied in case of successive read outs to erase any remnant of the previous radiation exposure if there is. Annealing is important in the sense that the measurement results obtained are exact consequences of the dose applied during irradiation. However, there are materials that are relieved of all radiation it is subjected to during the read out stage due to the applied heat. The radiation temperature and exposure time may show variety depending on the material. Annealing can also be referred to as thermal cleaning of the samples. For the case of lithium tetraborate researchers worked on a diversity of procedures. Table 1 shows different temperatures and retention times applied by different scientists for annealing.

Table 1. Annealing Procedures Applied to Lithium Tetraborate

\begin{tabular}{|l|c|c|}
\hline Researcher & Annealing Time & Annealing Temperature \\
\hline \hline Giesber et al., [43] & 100 seconds & $352^{\circ} \mathrm{C}$ \\
\hline Furetta [12] & 30 minutes & $300^{\circ} \mathrm{C}$ \\
\hline Xiong et al., [34] & & $450^{\circ} \mathrm{C}$ \\
\hline Lorrain et al., [38] & & $120^{\circ} \mathrm{C}$ \\
\hline Prokic [9] & 15 minutes & $650-700^{\circ} \mathrm{C}$ \\
\hline
\end{tabular}

In the radiation step, the sample is exposed to a previously calculated dosage of radiation that is optimum to detect the response. For the case of powder product, the weight of the sample to be measured possesses crucial importance. 
This is because the resultant response is directly related to the quantity of material. El-Faramawy et al. [39] determined the optimum weight interval as $5-10 \mathrm{mg}$ to gather the best glow curve illustrations depending on the study of Wall et al. [31] which displays the effect of sample weight on the TL signal as in Fig. (7).

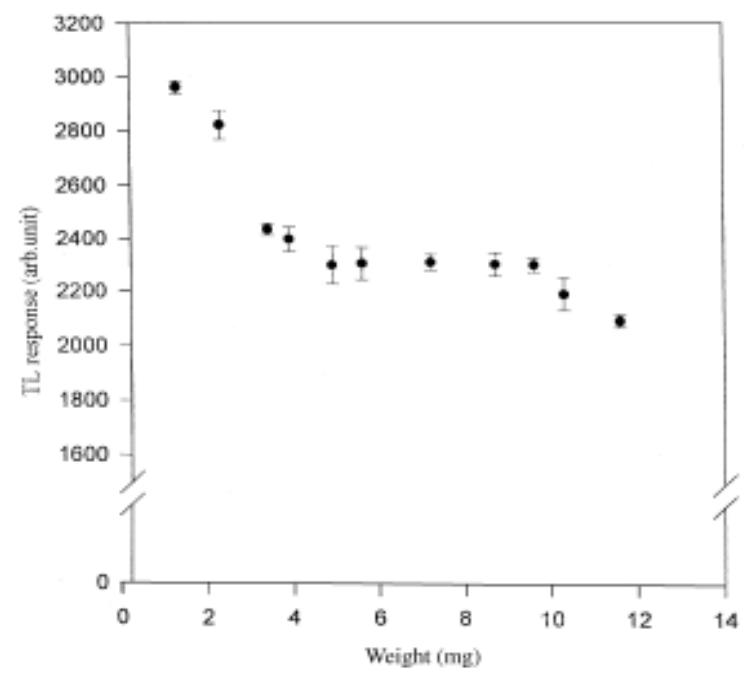

Fig. (7). The effect of sample weight on the TL signal.

The objective of the measurement determines the dose to be applied. In order to detect the dose threshold i.e. the minimum detectable dose, which gives a clue about the sensitivity of the material and is important for medical cases especially low doses are preferred. On the other hand, in order to determine the linearity of the response of the sample with respect to the radiation given a wide range of doses must be applied successively upon annealing. High radiation doses are preferable in order to analyze the glow curves in more detail. Srivastava [36] founded his studies on a radiation dose of $100 \mathrm{~Gy}$. Xiong [34] irradiated the samples from low doses as $0.1-1$ Gy up to 2000 Gy Holovey et al. [41,42] who based his studies on different annealing conditions worked on a moderate dose of $1.7 \mathrm{~Gy}$. In order to detect the existence of TL response a medium dose may be sufficient, for instance exposing lithium tetraborate doped with copper to 4.5 Gy radiations was found adequate [17].

Next step is the measurement of the response of the material. At this stage, special attention should be paid to the determination of the heating rate. Generally the heating rate for which the best resolved glow peaks are obtained is preferable. This rate is proved to be the lowest possible value. Ege et al. [13] who studied on lithium tetraborate doped with $\mathrm{Cu}, \mathrm{Ag}, \mathrm{P}$ investigated the TL results for heating rates of 1 , 2, 5, 10, 20 and $40 \mathrm{~K} / \mathrm{s}$. It was observed that TL peaks shifted towards higher temperature regions accompanied by a decrease in the intensity of the main peak with an increase in heating rate although the shapes of the glow curves did not display any change as a function of the heating rate. The other common heating rates employed for lithium tetraborate are $0.5 \mathrm{~K} / \mathrm{s}$ [41-43], $5^{\circ} \mathrm{C} / \mathrm{s}$ (Furetta et al., 2000), $6^{\circ} \mathrm{C} / \mathrm{s}$ [39], $2.90 \pm 0.03 \mathrm{~K} / \mathrm{s}[6], 1^{\circ} \mathrm{C} / \mathrm{sec}$ [17]. In all of the $\mathrm{TL}$ research made on lithium tetraborate the maximum temperature reached is around $400{ }^{\circ} \mathrm{C}$ since the main peak is expected around $200^{\circ} \mathrm{C}$.

The procedure followed for lithium triborate included radiation exposure of $4.5 \mathrm{~Gy}$. The sample was heated up to $400^{\circ} \mathrm{C}$ by the heating rate of $1{ }^{\circ} \mathrm{C} / \mathrm{sec}$. The annealing custom adopted was keeping the samples at oven annealing at 300, 350 and $400^{\circ} \mathrm{C}$ for $15 \mathrm{~min}$.

\subsection{Thermoluminescence Kinetic Parameters of Lithium Borate Compounds Activated with Metals}

Trapping parameters such as order of kinetics, trap-depth and the frequency factor have appreciable influence on the TL properties of a phosphor. Hence, knowledge of them is of paramount importance for understanding the TL phenomenon in the phosphor, and there have been many approaches in determining these parameters experimentally [44]. There are various methods of analysis developed for obtaining TL parameters such as heating rate, area measurement under the curve, glow curve shape etc. Karali group [44] studied on the kinetic parameters of $\mathrm{Li}_{2} \mathrm{~B}_{4} \mathrm{O}_{7}$ by isothermal decay (ID) and peak shape (PS) method (Table 2). TL glow curve of $\mathrm{Li}_{2} \mathrm{~B}_{4} \mathrm{O}_{7}: \mathrm{Cu}, \mathrm{Ag}, \mathrm{P}$ sample was recorded after irradiation with a $90 \mathrm{Sr}-90 \mathrm{Y}$ beta source for $1 \mathrm{~min}$. it seems reasonable that both methods, PS and ID and the measured parameters are reliable and accurate.

In order to find kinetic parameters of lithium triborate Yazıc1 [45] worked on the Al-doped $\mathrm{LiB}_{3} \mathrm{O}_{5}$. In their study, the additive dose (AD), initial rise with partial cleaning (IR), variable heating rate (VHR), peak shape (PS), three-points method (TPM) and computerized glow deconvolution (CGCD) methods were used to determine the kinetic parameters, namely the order of kinetics (b), activation energy (Ea) and the frequency factor (s) associated with the dosimetric thermoluminescent glow peak of Al-doped $\mathrm{LiB}_{3} \mathrm{O}_{5}$ after different dose levels with $\beta$-irradiation. Results in that paper indicate that the glow curve of Al-doped $\mathrm{LiB}_{3} \mathrm{O}_{5}$ after

Table 2. Kinetic Parameters of the Main Peak of $\mathrm{Li}_{2} \mathrm{~B}_{4} \mathrm{O}_{7}: \mathrm{Cu}$, Ag, P Dosimeter Obtained by Two Methods

\begin{tabular}{|c|c|c|c|c|}
\hline & Activation Energy $(\boldsymbol{E})$ & $(\mathbf{e V})$ & Frequency Factor $(s)$ & $\left(\mathbf{s}^{-1}\right)$ \\
\hline \hline PS method & $E_{\delta}$ & 1.13 & $s_{\delta}$ & $3.42 \times 10^{11}$ \\
\hline & $E_{\tau}$ & 1.13 & $s_{\tau}$ & $3.17 \times 10^{11}$ \\
\hline ID method & $E_{\omega}$ & 1.14 & $s_{\omega}$ & $4.01 \times 10^{11}$ \\
\hline
\end{tabular}


$\beta$-irradiation between 0.04 and $5 \mathrm{~Gy}$ in the temperature range from room temperature to $400{ }^{\circ} \mathrm{C}$ is the superposition of at least three glow peaks. On the other hand, when the dose level is increased above $5 \mathrm{~Gy}$, a new peak (peak 4) starts to generate at the high-temperature side of the main dosimetric peak. Kinetic order (b), activation energy (Ea) and frequency factor (s) of the main dosimetric peak were calculated by applying different experimental methods. In order to determine the kinetic order from the glow curve, the AD method was used firstly and it indicates that all of the glow peaks have first- order kinetics. Also Chen's peak shape method showed that the symmetry factor $\{\mu \mathrm{g} 1 / 4(\mathrm{~T} 2-\mathrm{Tm}) /(\mathrm{T} 2-\mathrm{T} 1)\}$ of the isolated glow peak 3 of Al-doped $\mathrm{LiB}_{3} \mathrm{O}_{5}$ has been found to be $0.42 \pm 1$, which gives a kinetic order of about $1.05 \pm 0.05$. A similar result was also obtained by the CGCD method. The values of the activation energy were calculated by using Gartia, Singh and Mazumdar's [46] PS method for different $\mathrm{x}$-values, the TP method developed by Rasheedy [47], the IR, VHR, CGCD and Chen's [48] PS methods. The results are the average values of the Ea values of $\mathrm{P} 3$ obtained by the TP, CGCD, VHR and PS methods of Chen and Gartia, Singh and Mazumdar give very close results which is about $1.05 \pm 0.05 \mathrm{eV}$. On the other hand, value of Ea obtained by the IR method gives slightly higher values as compared with those methods. One possible explanation for these differences is that the P3 does not originate from a discrete energy level and it is a distribution of traps. In reality, when the Tm_ Tstop procedure was checked it is seen that the position of peak slightly shifts toward the high-temperature side with increasing Tstop This result indicates that it has a distribution of traps and a heat treatment after irradiation may cause a variation in the activation energies of this peak.

\section{CONCLUSIONS AND SUGGESTIONS}

Thermoluminescent dosimetry makes use of the TL response of certain materials to measure exposure to radiation. Personnel dosimetry is an important area of study regarding the occupational safety of personnel employed especially in radiotherapy and nuclear stations. This article embraces the research conducted on production of lithium borates for the use in personnel dosimetry. The conclusions drawn from the evaluation of studies conducted up to date can be listed as:

1. Borates, both natural and synthesized, are important in high technology utilization areas.

2. Lithium tetraborate and lithium triborate are two borates that can be used in personnel dosimetry due to their TL properties.

3. Lithium tetraborate is produced in powder, glass, pellet and single crystal forms while lithium triborate is synthesized in powder form only. The synthesis and doping methods have effect on TL response on the material produced.

4. Lithium tetraborate has high sensitivity, low fading, linear dose response, low minimum detectable dose, easy annealing procedures. The TL properties of lithium triborate have not yet been determined.

5. Most important property of lithium borates regarding their use in personnel dosimetry is their effective atomic number equivalent to that of human tissue.
6. The dopants have an important effect on the TL response and properties of lithium tetraborate. There are various metals used as activators for lithium tetraborate and lithium triborate. Yet, the investigations on different dopants should pursue.

\section{GLOSSARY:}

$\begin{array}{ll}\text { Thermoluminescence = } & \begin{array}{l}\text { Illumination of a material upon } \\ \text { heating }\end{array} \\ \text { Dosimetry } & \begin{array}{l}\text { Measuring the dose of radiation } \\ \text { emitted from a source }\end{array} \\ = & \begin{array}{l}\text { An apparatus used to measure } \\ \text { radiation }\end{array} \\ = & \begin{array}{l}\text { Metal added into the matrix } \\ \text { material through a procedure to } \\ \text { trigger on enhance TL response }\end{array}\end{array}$

\section{REFERENCES}

[1] Z. T. Yu, Z. Shi, W. Chen, Y. S. Jiang, H. M. Yuan, and J. S. Chen, "Synthesis and $\mathrm{x}$-ray crystal structures of two new alkaline-earth metal borates: $\mathrm{SrBO}_{2}(\mathrm{OH})$ and $\mathrm{Ba}_{3} \mathrm{~B}_{6} \mathrm{O}_{9}(\mathrm{OH})_{6}$ ", J. Chem. Soc. Dalton -, vol. 9, pp. 2031-2035, 2002.

[2] D. A. Keszler, "Synthesis, crystal chemistry, and optical properties of metal borates", Curr. Opin. Solid State Mater Sci., vol. 4, pp. 155-162, 1999

[3] V. S. Gorelik, A. V. Vdovin, and V. N. Moiseenko, "Raman and Hyper-Rayleigh scattering in lithium tetraborate crystals", J. Russ. Laser. Res., vol. 24, pp. 553-605, 2003.

[4] P. Becker, "Borate materials in nonlinear optics", Adv. Mater., vol 10, pp. 979-992, 1998.

[5] P. Kumbhakar, and T. Kobayashi, "Nonlinear optical properties of $\mathrm{Li}_{2} \mathrm{~B}_{4} \mathrm{O}_{7}$ (LB4) crystal for the generation of tunable ultra-fast laser radiation by optical parametric amplification", Appl. Phys., vol. 78, pp. 165-170, 2004.

[6] B. M. Hunda, V. M. Holovey, I. I. Turok, and A. M. Solomon, "Effect of melt composition on the luminescent properties of czochralski-grown $\mathrm{Li}_{2} \mathrm{~B}_{4} \mathrm{O}_{7}$ single crystals", Inorg. Mater., vol. 41, pp. 1125-1129, 2005.

[7] V. G. Dimitriev, G. G. Gurzadyan, and D. N. Nikogosyan, Handbook of Nonlinear Optical Crystals, Springer:, Berlin, Heidelberg, New York: Verlag, 1997.

[8] H. König, and R. Hoppe, "Über Borati der Alkalimetalle. II. Zur Kenntnis von $\mathrm{LiB}_{3} \mathrm{O}_{5}$ ”, Z. Anorg. Allg. Chem, vol. 439, pp. 71-79, 1978.

[9] M. Prokic, "Lithium borate solid TL detectors", Radiat. Meas., vol. 33, pp. 393-396, 2001.

[10] A. S. Pradhan, "Thermoluminescence dosimetry and its applications", Radiat. Prot. Dosim., vol. 1, pp. 153-167, 1981.

[11] E. Betourne, and M. Toubou, "Synthesis of lithium borates as $\mathrm{LiB}_{3} \mathrm{O}_{5}$ by dehydration of hydrated precursors", J. Alloy Compd., vol. 255, pp. 91-97, 1997.

[12] C. Furetta, M. Prokic, R. Salamon, V. Prokic, and G. Kitis, "Dosimetric characteristics of tissue equivalent thermoluminescent solid TL detectors based on lithium borate", Nucl. Instrum. Methods, vol. 456, pp. 411-417, 2000.

[13] A. T. Ege, E. Ekdal, T. Karali, N. Can, and N. Prokic, "Effect of heating rate on kinetic parameters of B-Irradiated $\mathrm{Li}_{2} \mathrm{~B}_{4} \mathrm{O}_{7}: \mathrm{Cu}, \mathrm{Ag}, \mathrm{P}$ in TSL measurements", Meas. Sci. Technol., vol. 18, pp. 889-892, 2007.

[14] Sangeeta, B. Tiwari, and S. C. Sabharwal, "Investigations on the solidification behavior of $\mathrm{Li}_{2} \mathrm{~B}_{4} \mathrm{O}_{7}$ ", J. Cryst. Growth, vol. 273, pp. 167-171, 2004.

[15] V. Jubera, J. P. Chaminade, A. Garcia, F. Guillen, and C. Fouassier, "Luminescent properties of $\mathrm{Eu}^{3+}$-activated lithium rare earth borates and oxyborates", J. Lumin., vol. 101, pp. 1-10, 2003.

[16] T. T. Cuong, P. T. Dung, Q. Hain, V. T. T Ha, N. M. Hung, N. T. Khoi, N. X. Ku, V. X. Quang, N. T. Thanh, and N. Q. Thanh, "Preparation and dosimetric characterization of some thermallystimulated luminescence materials in the radiotherapy", 
In Proc. The Ninth Asia Pacific Physics Conference. Hanoi, Vietnam, 2004.

[17] E. Pekpak, "Synthesis and characterization of lithium tetraborate doped metals", M. S. Thesis, Middle East Technical University, Turkey 2009.

[18] C. A. Jaychandran, "The response of thermoluminescent dosimetric lithium borates equivalent to air, water and soft tissue and of $\mathrm{LiF}$ TLD-100 to low energy X-Rays", Phys. Med. Biol., vol. 15, pp. 325-334, 1970.

[19] M. Voda, R. Balda, M. Al-Saleh, I. S. Ocariz, M. Cano, G. Lobera, and E. Macho, "Optical properties of $\mathrm{Pr}$-doped lithium tetraborate glasses", J. Alloy. Compd., vol. 323, pp. 250-254, 2001.

[20] S. M. Kaczmarek, " $\mathrm{Li}_{2} \mathrm{~B}_{4} \mathrm{O}_{7}$ glasses doped with $\mathrm{Cr}, \mathrm{Co}$, Eu and Dy", Opt. Mater., vol. 19, pp.189-194, 2002.

[21] J. Manam, and A. S. K. Sharm, "Evaluation of trapping parameters of thermally stimulated luminescence glow curves in $\mathrm{Cu}$-Doped $\mathrm{Li}_{2} \mathrm{~B}_{4} \mathrm{O}_{7}$ phosphor", Radiat. Phys. Chem., vol. 72, pp. 423-427, 2004.

[22] Z. Özdemir, G. Özbayoğlu, and A. Yılmaz, "Investigation of thermoluminescence properties of metal oxide", J. Mater. Sci., vol. 42, pp. 8501-8508, 2007.

[23] B. Ardıçoğlu, G. Özbayoğlu, Z. Özdemir, and A. Yılmaz, "Production and identification of rare-earth doped lithium triborate", J. Alloy. Compd., vol. 418, pp.77-79, 2006.

[24] A. Gurga, J. Tuliano, Y. Gogotsi, and S. N. Dub, "The mechanical properties of lithium tetraborate (100), (011) and (112) faces", Mater. Lett., vol. 61, pp.770-773, 2007.

[25] T. Sugawara, R. Komatsu, and U. Satoshi, "Linear and nonlinear optical properties of lithium tetraborate", Solid State Commun., vol. 107, pp. 233-237, 1998.

[26] K. Mahesh, P. S. Weng, and C. Furetta. Thermoluminescence In Solids And Its Applications. Nuclear Technology Publishing: Ashford, 1989.

[27] R. Chen, and S. W. S. Mckeever. Theory of thermoluminescence and related phenomena. World Scientific: Singapoure, 1997.

[28] V. Kortov, "Materials for thermoluminescent dosimetry: current status and future trends", Radiat. Meass., vol. 42, pp. 576-581, 2007.

[29] C. Furetta. Handbook of Thermoluminescence. World Scientific: New Jersey, London, Singapore, Hong Kong, 2003.

[30] M. Prokic, "Dosimetric characteristics of $\mathrm{Li}_{2} \mathrm{~B}_{4} \mathrm{O}_{7}: \mathrm{Cu}, \mathrm{Ag}, \mathrm{P}$ solid TL detectors", Radiat. Prot. Dosim., vol. 33, pp. 265-268, 2002.

[31] B. F. Wall, C. M. H. Driscoll, J. C. Strong, and E. S. Fisher, "The suitability of different preparations of thermoluminescent lithium borate for medical dosimetry", Phys. Med. Biol., vol. 27, pp. 10231034, 1982.

[32] A. C. Fernandes, M. Osvay, J. P. Santose, V. Holovey, M. Ignatovych, "TL properties of newly developed lithium tetraborate single crystals", Radiat. Meas., vol. 43, pp. 476-479, 2008.
[33] T. Depçi, G. Özbayoğlu, A. Yılmaz, and N. Yazıcı, "The thermoluminescent properties of lithium triborate", Nucl. Instrum. Methods, vol. 266, pp. 755-762, 2008

[34] Z. Y. Xiong, C. X. Zhang, and Q. Tang, "Thermoluminescence characteristics of $\mathrm{Li}_{2} \mathrm{~B}_{4} \mathrm{O}_{7}: \mathrm{Cu}, \mathrm{Ag}, \mathrm{P}$ ", Chin. Sci. Bull., vol. 52, pp. 1776-1779, 2007.

[35] K. S. Park, J. K. Ahna, D. J. Kima, H. K. Kima, and H. Y. H. Wanga, "Growth and properties of $\mathrm{Li}_{2} \mathrm{~B}_{4} \mathrm{O}_{7}$ single crystals", $J$. Cryst. Growth, vol. 249, pp. 483-486, 2002.

[36] J. K. Srivastava, and S. J. Supe, "Thermoluminescence characterization of $\mathrm{Li}_{2} \mathrm{~B}_{4} \mathrm{O}_{7}$ doped with $\mathrm{Cu}$ ", J. Phys. D: Appl. Phys., vol. 22, pp. 1537-1543, 1989.

[37] C. M. H. Driscol, E. S. Fisher, C. Furetta, E. Padovani, D. J. Richards, and B. F. Wall, "Thermoluminescence properties of lithium borate dosemeters", Radiat. Prot. Dosim., vol. 6, pp. 305308, 1983.

[38] S. Lorrain, J. P. David, R.Visocekast, and G. Marinello, "A study of new preparations of radiothermoluminescent lithium borates with various activators", Radiat. Prot. Dosim., vol. 17, pp. 385-392, 1986.

[39] N. A. El-Faramawy, S. U. El-Kameesy, A. El-Agramy, and G. Metwally, "The dosimetric properties of in-house prepared copper doped lithium borate examined using the tl-technique", Radiat. Phys. Chem., vol. 19, pp. 9-13, 2000.

[40] M. Kayhan, "Effect of synthesis and doping methods on thermoluminescence glow curves of manganese doped lithium tetraborate", M. S. Thesis, Middle East Technical University, Turkey, 2009.

[41] V. M. Holovey, V. I. Sidey, V. I. Lyamayev, and P. P. Puga, "Influence of reducing annealing on the luminescent properties of $\mathrm{Li}_{2} \mathrm{~B}_{4} \mathrm{O}_{7}: \mathrm{Cu}$ single crystals", J. Lumin., vol. 126, pp. 408-412, 2007.

[42] V. M. Holovey, V. I. Sidey, V. I. Lyamayeva, and M. M. Birova "Influence of different annealing conditions on the luminescent", $J$. Phys. Chem. Solids, vol. 68, pp. 1305-1310, 2007.

[43] H. G. Giesber, J. Ballato, and W. T.Pennington, "Synthesis and characterization of optically nonlinear and light emitting lanthanide borates", Inform. Sci., vol. 149, pp. 61-68, 2003.

[44] A. T. Ege, E. Ekdal, T. Karali, and N. Can "Determination of Thermoluminescence kinetic parameters of $\mathrm{Li}_{2} \mathrm{~B}_{4} \mathrm{O}_{7}: \mathrm{Cu}, \mathrm{Ag}, \mathrm{P}$ ", Radiat. Meass., vol. 149, pp. 1280-1284, 2007.

[45] V. E. Kafadar, A. N. Yazici, and R. G. Yildirim, "Determination of trapping parameters of dosimetric thermoluminescent glow peak of lithium triborate $\left(\mathrm{LiB}_{3} \mathrm{O}_{5}\right)$ activated by aluminum”, J. Lumin., vol. 129, pp. 710-714, 2009.

[46] T. S. C. Singh, P. S. Mazumdar, and R. K. Gartia, "Determination of activation energy from the shape of a thermoluminescence peak", J. Phys. D: Appl. Phys., vol. 21, pp. 815-819, 1988.

[47] M. S. Rasheedy, "A new evaluation technique for analyzing the Thermoluminescence glow curve and calculating the trap parameters", Thermochim. Acta, vol. 429, pp. 143-147, 2005.

[48] R. Chen, and S. W. S. McKeever, Theory of Thermoluminescence and Related Phenomena. World Scientific: Singapore, 1997. 